\title{
A structural equation model of tourism activities, social interaction and the impact of tourism on youth tourists' QOL
}

\section{Celeste Eusébio*, Maria João Carneiro and Ana Caldeira}

Department of Economics, Management and Industrial Engineering, University of Aveiro,

Campus Universitário de Santiago,

3810-193 Aveiro, Portugal

Fax: 00351-234-370215

Email: celeste.eusebio@ua.pt

Email: mjcarneiro@ua.pt

Email: anacaldeira@ua.pt

*Corresponding author

\begin{abstract}
The current study aims to develop a model in the scope of youth tourism that illustrates structural relationships among the following constructs: 1) frequency of participation in several tourism activities; 2) frequency of social interaction with residents; 3) perception of tourism impacts on several domains of quality of life (QOL); 4) perception of tourism impacts on overall QOL. To achieve this objective, a survey was carried out with university students and 412 completed questionnaires were obtained. The model was tested with partial least squares structural equation modelling (PLS-SEM). Results show a strong positive impact of tourism activities on social interaction and a positive impact of both tourism activities and social interaction on all domains of QOL - physical health, social relationships, psychological features and environmental conditions. The paper ends with recommendations for improving the impact of tourism on youth visitors' QOL.
\end{abstract}

Keywords: tourism activities; social interaction; quality of life; QOL; tourism impacts; youth tourism market; partial least squares structural equation modelling; PLS-SEM.

Reference to this paper should be made as follows: Eusébio, C., Carneiro, M.J. and Caldeira, A. (2016) 'A structural equation model of tourism activities, social interaction and the impact of tourism on youth tourists' QOL', Int. J. Tourism Policy, Vol. 6, No. 2, pp.85-108.

Biographical notes: Celeste Eusébio is an Assistant Professor of Tourism and a researcher at the GOVCOPP Research Unit at the University of Aveiro, Portugal. She holds a Degree in Tourism Management and Planning from the University of Aveiro (1995), a Master in Economics from the University of Coimbra (1998) and a Doctoral Degree in Tourism, also from the University of Aveiro (2006). Her research interests include tourism economics, tourism impacts, tourism forecasts and consumer behaviour in tourism. She is currently the coordinator of the Degree in Tourism at the University of Aveiro. 
Maria João Carneiro is Assistant Professor of Tourism and researcher at the GOVCOPP Research Unit at the University of Aveiro, Portugal. She holds a Degree in Tourism Management and Planning from the University of Aveiro (1993), an MBA from the New University of Lisbon (1998) and a Doctoral Degree in Tourism, also from the University of Aveiro (2007). Her research interests include competitiveness in tourism, tourism impacts, image and positioning of tourism destinations, consumer behaviour in tourism and tourism destination marketing. She is currently the vice-coordinator of the Degree programme in Tourism at the University of Aveiro.

Ana Caldeira is Assistant Professor of Tourism and researcher at the GOVCOPP Research Unit at the University of Aveiro, Portugal. She holds a Degree in International Relations from the Technical University of Lisbon (1997), a Master in Tourism Management and Development from the University of Aveiro (2006) and a Doctoral Degree in Tourism, also from the University of Aveiro (2014). Her research interests include visitor management, tourist spatial behaviour, tourist attractions, competitiveness in tourism and tourism destination marketing.

This paper is a revised and expanded version of a paper entitled 'Tourism activities, social interaction and the impact of tourism on youth tourists' QOL: a structural equation model' presented at ICOT2015 - From Tourism Policy into Practice: Issues and Challenges in Engaging Policy Makers and End Users, London, 24-27 June 2015.

\section{Introduction}

The impact of tourism on quality of life (QOL) of both residents and tourists has become an important research topic in recent decades (Andereck and Nyaupane, 2011; Dolnicar et al., 2013). Moreover, the youth market is a relevant and growing tourism market segment that is still at the beginning of a potentially long tourism career (Bicikova, 2014; Richards, 2007). The great potential of tourism to improve QOL is also recognised. However, there is little research on the impact of tourism on QOL of the youth market. As Dolnicar et al. (2013) highlight, QOL is an individual and a dynamic concept, revealing the importance of analysing the impact of tourism on QOL of several tourism markets.

The study of the impact of tourism on youth tourists' QOL and of the factors related to tourism experience that may influence this impact is of utmost relevance for academics, politicians and tourism industry staff. For managers and planners of tourism destinations, information concerning the impact of tourism on tourists' QOL and the factors that may influence this impact are insights of utmost relevance for designing successful tourism development strategies.

Despite some research about the impact of tourism on tourists' QOL (e.g., Dolnicar et al., 2013; Eusébio and Carneiro, 2011; Moscardo, 2009), the literature regarding the relationship between tourism and QOL remains fragmented and in a stage of infancy. Moreover, few studies analyse the impact of tourism on youth tourists' QOL and the factors that may influence this impact. Furthermore, the literature review reveals an absence of empirical studies analysing the causal relationship among tourism activities carried out during a trip, tourist-host social interaction and impact of tourism on youth 
tourists' QOL. The present study aims to overcome this gap, developing a structural equation model to analyse the relationships between two important dimensions of youth tourism experience (tourism activities carried out during a trip and tourist-host interaction) and the impact of tourism on youth tourists' QOL (both in terms of QOL domains and of overall QOL).

To accomplish the objectives of this paper, following this introduction, a literature review about some characteristics of the youth tourism market and regarding the three constructs analysed in this research - types of tourism activities carried out by youth tourists during a trip, tourist-host interaction and the potential impact of tourism on tourists' QOL - is provided. Further, the research model and hypotheses are reported. The data collection methods and the data analysis methods used to test the structural research model proposed are described. Finally, the results of the empirical study are presented and discussed. The paper ends with the most important insights of this research in order to provide guidelines to increase the impact of tourism on youth tourists' QOL. Limitations of this research and suggestions for future studies to increase the knowledge in this issue will also be provided.

\section{Literature review}

\subsection{Youth tourism market}

The youth market is growing and is expected to be responsible for about 300 million international youth trips per year in 2020 (WYSE Travel Confederation/UNWTO, 2011). The number of returning trips to destinations is likely to be higher in this market, which is in the early stages of its travel cycle. The youth market is also very important since it is likely to be more fearless than other segments and, consequently, more resilient to natural features and acts of terrorism (Richards, 2007; WYSE Travel Confederation/UNWTO, 2011).

Some very important travel motivations of young visitors are being entertained and novelty (having new experiences, including visiting new destinations and learning something new) (Bicikova, 2014; Kim and Jogaratnam, 2002; Ryan and Zhang, 2007; Xu et al., 2009). Another important travel motivation, which is highly related to novelty, is increasing knowledge, namely by learning new things and knowing other cultures (Kim and Jogaratnam, 2002; Tourism Research and Marketing, 2013; Xu et al., 2009). For many youth visitors, tourism trips are also seen as good opportunities for relaxing (Bicikova, 2014; Kim and Jogaratnam, 2002; Ryan and Zhang, 2007; Xu et al., 2009) and for socialising (Bicikova, 2014; Kim and Jogaratnam, 2002; Richards, 2007). The importance of socialisation for the youth tourism market will be further analysed in Section 2.3.

Nowadays, young visitors already have considerable travel experience - about six international short trips and five long trips (with more than seven nights) in a five-year period (Tourism Research and Marketing, 2013). In the planning of the trip young visitors usually assign high importance to value for money and cheap travel options, (Bicikova, 2014; Phau et al., 2010; Richards, 2007), and frequently use internet and family or friends as information sources (Richards, 2007; Ryan and Zhang, 2007; Xu et al., 2009). When traveling, the youth tourism market often uses hotel or other cheaper, or 
even free, means of accommodation - e.g., hostels, camping and houses of friends and relatives (Richards, 2007; Xu et al., 2009) - and carries out a wide range of tourism activities. Tourism trips were revealed to have important impacts on the youth tourism market. They contributed to a great appreciation and understanding of other cultures, to a higher self-knowledge and self-awareness and, in certain cases, even to change the lifestyle, strengthen values and change career options (Richards, 2007).

\subsection{Tourism activities carried out during a trip}

The participation in tourism activities is an important component of the tourism experience (Kim, 2010). Several studies (e.g., Richards, 2007; WYSE Travel Confederation/UNWTO, 2011) attest that youth visitors tend to participate in a high number of activities during tourism trips.

Some of the preferred tourism activities of youth visitors are going to beach (Bicikova, 2014; Frändberg, 2010; Kim and Jogaratnam, 2003; Thrane, 2008; Xu et al., 2009) and sightseeing (Bicikova, 2014; Frändberg, 2010; Kim and Jogaratnam, 2003; Shanka et al., 2002). Visiting cities and shopping are also popular activities in this market segment (Thrane, 2008; Xu et al., 2009). Despite the fact that young visitors tend to appreciate many other tourism activities such as cultural activities (e.g., visiting museums, historic sites, participating in cultural events), nature activities, fun activities (e.g., eating and drinking, going to nightclubs) and sports activities, more heterogeneity seems to exist regarding the willingness to undertake the aforementioned kinds of activities (Bicikova, 2014; Frändberg, 2010; Kim and Jogaratnam, 2003; Richards, 2007; Ryan and Zhang, 2007; Thrane, 2008; Xu et al., 2009). Even though the youth market reveals a high propensity to engage in tourism activities compared to other market segments, research also shows some variability in this market, regarding the willingness to undertake tourism activities. Literature reveals that the participation of young people in tourism activities depends on many factors such as sociodemographic (e.g., age, nationality) and motivations (Eusébio and Carneiro, 2012; Ryan and Zhang, 2007; Tangeland, 2011; Thrane, 2008; Xu et al., 2009). Additionally, the comparison of studies carried out in different countries (e.g., Frändberg, 2010; Kim and Jogaratnam, 2003; Xu et al., 2009) also suggests that the characteristics of the destination may also influence young visitors' involvement in activities during tourism trips.

The propensity to participate in a high number of activities is also associated with higher expenditures (Finsterwalder and Laesser, 2013; Tangeland, 2011). Moreover, the practice of tourism activities may also help satisfy several motivations of visitors, such as novelty, expanding knowledge, making contact with other cultures and socialising (e.g., Eusébio and Carneiro, 2012; Ryan and Zhang, 2007; Su et al., 2014; Tangeland, 2011). Therefore, ensuring that destinations provide appropriate conditions for practising the tourism activities that fulfil the needs of their target markets is of remarkable importance, in order to boost the positive impacts of tourism for both destinations and the visitors. Considering that young visitors have a high motivation for social contact, as previously mentioned, the next section will discuss the relevance and characteristics of social interaction in the scope of tourism. 


\subsection{Tourist-host interaction}

Social contact between tourists and hosts is a critical factor for tourism experience, simultaneously influencing tourists' and hosts' satisfaction (Eusébio and Carneiro, 2012; Kastenholz et al., 2013; Reisinger and Turner, 2003; Sinkovics and Penz, 2009). This concept is complex and has been the object of several definitions. However, as suggested by Reisinger and Turner (2003, p.37) social contact in tourism can be defined as "the personal encounter that takes place between a tourist and a host". Frequently, tourist-host interaction is brief, formal, temporary, non-repetitive, open to deceit, exploitation and mistrust, unequal and unbalanced in terms of its meanings for both sides (De Kadt, 1979; Eusébio and Carneiro, 2012; Kastenholz et al., 2013; Reisinger and Turner, 2003; Reisinger, 2009; Sinkovics and Penz, 2009). However, studies on the youth market reveal that socialising and knowing other cultures emerge as important travel motivations of young visitors (e.g., Bicikova, 2014; Eusébio and Carneiro, 2012; Kim and Jogaratnam, 2002; Xu et al., 2009;). Consequently, young tourists may look for a special relationship with their hosts in order to obtain information and to gain deeper knowledge regarding the values, customs and cultural assets of the host communities.

The literature review about tourist-host interaction research reveals that this is a recent field of research, with a lack of both theoretical foundation and empirical studies (Eusébio and Carneiro, 2012). The few studies carried out in this field (e.g., Eusébio and Carneiro, 2012; Kastenholz et al., 2013; Murphy, 2001; Pizam et al., 2000; Reisinger and Turner, 1998; Sinkovics and Penz, 2009) suggest that there is no consensus in terms of how to measure this construct, what factors may determine the intensity and nature of encounters between tourists and hosts and what the consequences of these encounters are.

In terms of indicators to measure tourist-host interaction some studies used the intensity of interaction to measure this construct (e.g., Pizam et al., 2000), while others used the frequency of interaction in several contexts (e.g., Eusébio and Carneiro, 2012; Kastenholz et al., 2013). There are also some studies (e.g., Reisinger and Turner, 1998) that analysed types of social contact preferred by visitors. In order to assess this construct it is of paramount relevance to consider that there are several contexts, as De Kadt (1979) emphasises, where tourist-host encounters occur, such as when tourists and hosts exchange information and ideas, when they use the same tourist attractions and facilities and when tourists acquire goods and services from hosts.

Studies that analyse the factors that may influence the tourist-host interaction in the youth tourism market are very scarce. Eusébio and Carneiro's (2012) study is one of the few published studies that identifies determinants related to university student tourists (travel motivations, travel behaviour, cultural familiarity and similarity, tourists' perceptions of tourism impacts and sociodemographic profile) which influence touristhost interaction. However, in the general literature about tourist-host interaction (e.g., Kastenholz et al., 2013; Pizam et al., 2000; Reisinger and Turner, 1998; Reisinger, 2009; Sinkovics and Penz, 2009), the socio-demographic profile and cultural background of both participants in the contact, travel motivations, cultural familiarity and similarity and perceived costs and benefits of the contact stand out as important factors influencing tourist-host interaction. From this literature review, the researches that examine the impact of tourism activities carried out during a trip on tourist-host interaction are generally fragmented and restricted to certain tourism activities. 
Regarding the consequences of tourist-host interaction, the studies carried out in this field focused mainly on the impact of tourist-hosts encounters on visitors' satisfaction and on their intention to return and, also, on hosts' satisfaction (e.g., Andereck et al., 2005; Pizam et al., 2000; Reisinger and Turner, 2003; Sinkovics and Penz, 2009). Studies that examine the impact of tourist-host interaction on tourists' perceptions of impacts of tourism on their QOL are very scarce.

\subsection{Impact of tourism on $Q O L$}

There is no consensus in the literature regarding the concept of QOL (Sirgy et al., 2006). Several words have been used as synonyms of this concept, such as well-being and people's satisfaction with life. According to Theofilou (2013) the QOL concept can be seen as the individual's perceptions of how good his(her) life is. This overall concept of good life includes several domains (e.g., work, family, leisure, social relationships, income and health). Then, it is possible to observe that, on the one hand, the opportunity to participate in tourism activities is already an important domain of people's QOL and that, on the other hand, tourism has a great potential to improve other domains of QOL (e.g., social relationships and health). Despite the potential positive impact of tourism on people's QOL, little knowledge has been generated in this field. Moreover, studies that examine the factors that may influence the impact of tourism on youth tourists' QOL are very limited. However, an increase in research on the role of tourism on tourists' QOL has been observed in the last decade (e.g., Carneiro and Eusébio, 2011; Dann, 2002; Dolnicar et al., 2013; Eusébio and Carneiro, 2011; McCabe et al., 2010; Michalkó et al., 2009; Moscardo, 2009; Nawijn et al., 2010; Sirgy et al., 2011). Studies carried out in this field show that tourism may influence positively and negatively the QOL of each tourist (McCabe et al., 2010; Moscardo, 2009). The nature and magnitude of the impact of tourism on youth tourists' QOL will depend not only on individuals' psychological and socio-demographic characteristics but also on their travel behaviour. However, the results of the few studies that, to date, examine the factors that influence the impact of tourism on tourists' QOL are not consensual (e.g., Alexander et al., 2010; Dolnicar et al., 2013; Eusébio and Carneiro, 2011).

Travel motivations emerge as one of the most analysed potential determinants of the impact of tourism on QOL. Despite the tourism activities carried out during a trip and the tourist-host interaction being identified as two important dimensions of tourism experience, a very limited number of studies have analysed their influence on youth tourists' QOL. Moreover, no study was found using structural equation modelling to analyse the impact of tourism activities carried out and tourist-host interaction on tourism impacts perceived by youth tourists on their QOL.

To measure the impact of tourism on youth tourists' QOL, it is of utmost relevance to select the most suitable indicators to measure this construct. The QOL literature reveals that this is a complex and multidimensional concept that can be measured through objective and subjective measures (Dann, 2002; Eusébio and Carneiro, 2011; McCabe et al., 2010; Michalkó et al., 2009; Neal et al., 2004; Sirgy et al., 2011). Consequently, in tourism studies several procedures have been used to assess the impact of tourism on tourists' QOL. The majority of studies published, in order to capture the impact of tourism on several domains of QOL, frequently use scales with several items (e.g., Dolnicar et al, 2013; McCabe et al., 2010). The WHOQOL-BREF scale, a short version of the WHOQOL-100 used by the World Health Organization to measure QOL 
worldwide, has been used in some studies that analyse the impact of tourism on tourists' QOL (e.g., Eusébio and Carneiro, 2011; McCabe et al., 2010). However, the potential of the WHOQOL-BREF scale is largely unexplored in tourism research. Consequently, given that in this study QOL is understood as an individual's subjective evaluation of several life domains (e.g.. physical health, psychological state, social relationships, financial resources), an adapted version of the WHOQOL-BREF scale was used to measure the impact of tourism on youth tourists' QOL.

\section{Research model and hypotheses}

In order to study the relationship between tourism activities carried out during a trip, tourist-host interaction and impact of tourism on youth tourists' QOL, the conceptual model presented in Figure 1 was designed. The model hypothesises relationships among seven latent constructs. The empirical study presented in this paper aims to test the research model proposed and the hypotheses through structural equation modelling.

Figure 1 Research model proposed (see online version for colours)

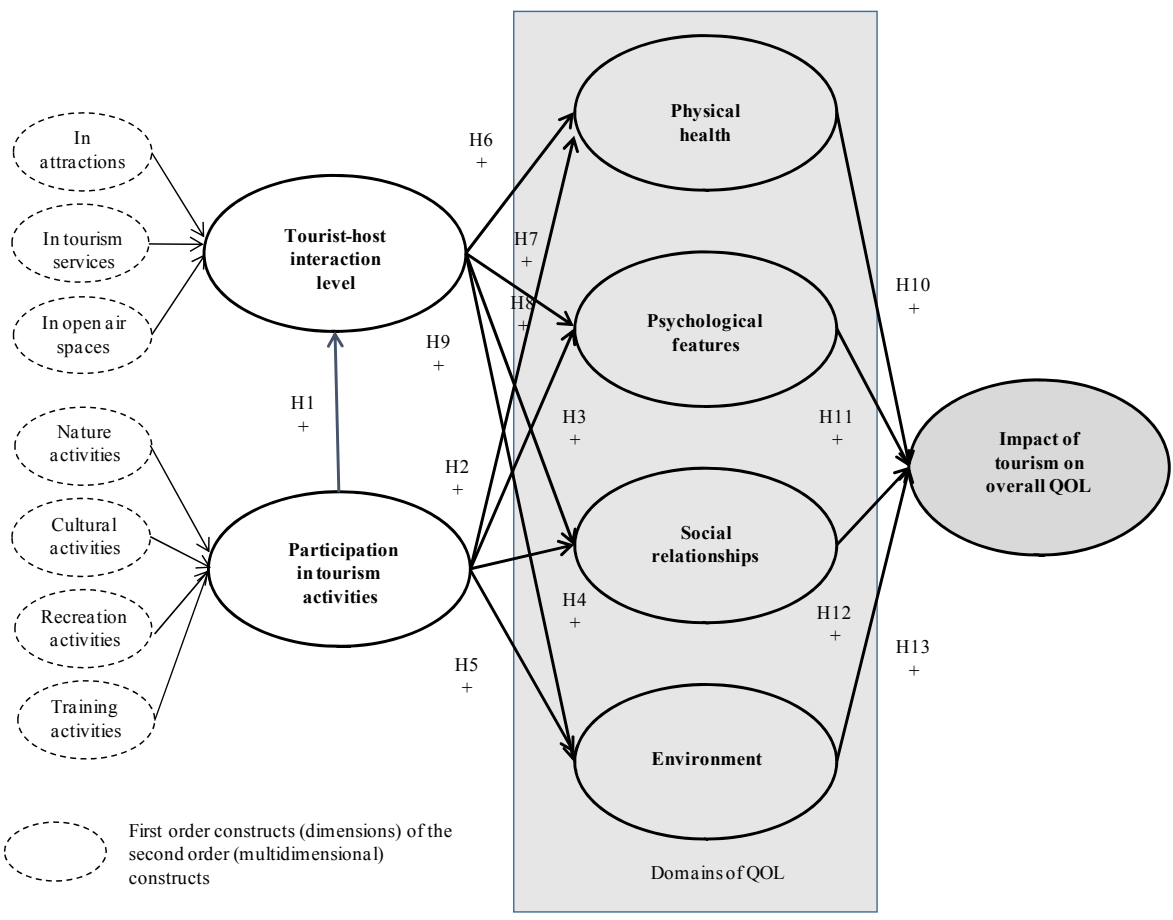

\subsection{Participation in tourism activities and tourist-host interaction level}

Some studies (e.g., Tangeland, 2011) reveal that obtaining social benefits (e.g., meeting new people) is already, for several segments of visitors, an important motivation to participate in tourism. Participating in one activity may enable tourists to meet new people who perform the same activity (Tangeland, 2011), especially if the activity is 
carried out in groups. Tangeland and Aas's (2011) research suggests that participation in nature-based activities is more related to the facilitation of people's integration (e.g., the activity being organised or being a group activity) than it is to other characteristics like the activity being designed for families or children, providing learning opportunities or permitting one to experience risk or challenges. It also highlights that facilitation of integration is more important for some visitors such as single-parents, couples without children and singles.

Contact with local residents may be of special value to visitors since the residents frequently hold relevant knowledge about the destination (Su et al., 2014), being thus able to act as cultural brokers, disseminating information about the destination, namely on local customs, local products and typical activities (Kastenholz et al., 2013). According to $\mathrm{Su}$ et al. (2014) the travel behaviour of tourists may affect the type of tourist-host interaction, including its intensity, and some tourism activities (e.g., visiting local families, dancing, singing, taking photos with local clothes) serve as a platform for tourist-host interactions. Kim (2012) also found that engagement in recreation activities is very important to experience close social contact with people having different cultural or ethnic backgrounds.

A small number of previous studies also show that the visitors with a highest propensity to participate in a considerable number of activities, or to undertake them most frequently, have the highest interaction with local residents (Carneiro and Eusébio, 2011; 2012). This highest propensity is not only due to engaging in activities together with residents, but also because some activities promote formal interaction with residents in their workplace (e.g., buying products or buying entrance tickets when visiting tourism attractions) or informal, in other sites of the destination (e.g., when asking for information about a specific activity). Hence, some researchers provide evidence that walking in the street and going to food and beverage establishments to eat and drink provide considerable opportunities for tourist-host contacts (Carneiro and Eusébio, 2011; 2012; Kastenholz et al., 2013). Opportunities for tourist-host interaction when visiting tourism attractions seem to be still reduced in the majority of tourism attractions, although there is some evidence of interesting social contacts in specific attractions, such as events (Carneiro and Eusébio, 2012; Kastenholz et al., 2013). The research of Bond et al. (2015) on religious tourism shows that, although not all activities promote equal levels of social contact, some activities, namely visiting certain attractions, foster a considerable interaction and provide a major contribution to relationship building. Thus, it is hypothesised that:

H1 Participation in tourism activities will have a positive effect on tourist-host interaction.

\subsection{Participation in tourism activities and the impact of tourism on several domains of youth tourists' $Q O L$}

Research on the influence of tourism activities on QOL has been much neglected. Nevertheless, it is recognised that undertaking physical activities (e.g., sports activities) during tourism trips, in a different place and, especially, in unpolluted environments, may help develop physical skills, reduce stress and increase physical health (Moscardo, 2009). Some visitors report that their participation in physical activities is largely due to health 
and fitness reasons and, sometimes, to test their physical abilities (Sibson et al., 2010; Szczechowicz, 2012).

Undertaking leisure activities with other persons is also likely to boost life satisfaction (Trainor et al., 2010). Many people also associate physical leisure activities with pleasure, fun, enjoyment and refreshment, remarking the important role these activities could have in promoting psychological wellbeing (Sibson et al., 2010). Moreover, Wei and Milman's research (2002) highlights the existence of a significant positive relationship between the number of activities in which senior visitors participate and the seniors' level of psychological wellbeing.

By promoting social interaction, tourism activities can also have an important role in contributing towards meeting new people and, thus, expanding social networks, as well as spending quality time and carrying out activities alongside other persons, permitting them to develop social skills (reducing difficulties in adapting to and interacting with others and developing interpersonal social skills) and strengthening social bonds (Moscardo, 2009; Sirgy et al., 2011; Tse, 2014). As Su et al. (2014) posit, the interaction between tourists and hosts may evolve until a stage where there is an intense interaction and both of these stakeholders fulfil their social needs. Some studies provide evidence that tourism activities have a very important role in promoting mutual understanding, since they permit a deeper knowledge of other cultures, greater openness of mind and better understanding of cultural differences (Kim, 2012; Su et al., 2014), contributing to an increased respect for people with other cultures and to the emergence of more positive relationships (Richards, 2007).

Undertaking activities during tourism trips expands leisure opportunities, permitting access to other leisure resources and, sometimes, to spend time in healthier environments where it is possible to come into contact with nature (Szczechowicz, 2012). Moreover, engaging in certain activities such as cultural activities (e.g., visiting museums, visiting historic sites, participating in events), educational activities (e.g., studying languages) or even physical activities may induce some changes regarding one's environment. They may permit a deeper knowledge of other places and customs, making contact with different ways of life (Kim, 2012; Su et al., 2014) and may bring other potential benefits of tourism already identified by some authors (Kim, 2012; Sirgy et al., 2011; Tse, 2014), such as developing certain skills - e.g., developing time-management and language skills, an increased ability to manage life and to make decisions - and developing more positive attitudes towards the environment - e.g., being more positive concerning work, being more available to adapt to new environments. Thus, it is hypothesised that:

H2 Participation in tourism activities will have a positive effect on perceived tourism impacts on physical health.

H3 Participation in tourism activities will have a positive effect on perceived tourism impacts on psychological features.

H4 Participation in tourism activities will have a positive effect on perceived tourism impacts on social relationships.

H5 Participation in tourism activities will have a positive effect on perceived tourism impacts on environment. 


\subsection{Tourist-host interaction and impact of tourism on several domains of youth tourists' $Q O L$}

Despite the limited literature analysing the effect of tourist-host interaction on several domains of youth tourists' QOL, some empirical evidence suggests that these encounters will influence the two actors of this process (tourists and hosts) ( $\mathrm{Su}$ et al., 2014). Andereck and Nyaupane's (2011) study reveals that when residents have contact with visitors on a frequent basis, they view tourism in a much more positive light. On the other hand, Alexander et al. (2010) show that interactions with people on holidays influence tourists. Tourism trips provide tourists with opportunities for coming into contact with other cultures, contributing to improving their social skills, cultural enrichment and learning. Moreover, Pizam et al. (2000) emphasise that maintaining a positive and intensive tourist-host interaction is critical for creating rewarding tourism experiences. Then, despite the limited research in this field, in this study it is postulated that the more intense and intimate the encounters between tourists and residents, the higher the young tourists' perceptions are of the impacts of tourism on their QOL. However, some differences are expected in terms of QOL domains influenced by tourist-host interaction. Based on the aforementioned arguments the following hypotheses were postulated.

H6 Frequency of tourist-host interactions will have a positive effect on perceived tourism impacts on physical health.

H7 Frequency of tourist-host interactions will have a positive effect on perceived tourism impacts on psychological features.

H8 Frequency of tourist-host interactions will have a positive effect on perceived tourism impacts on social relationships.

H9 Frequency of tourist-host interactions will have a positive effect on perceived tourism impacts on environment.

\subsection{Impact of tourism on several domains of youth tourists' $Q O L$ and impact of tourism on their overall $Q O L$}

Besides the complex and multifaceted nature of the QOL concept, there is some consensus that the domains of QOL are related to:

1 physical health - physical pains, energy, mobility

2 psychological wellbeing - e.g., spiritual life, hedonic level of affect

3 social relationships - with family, friends and other people

4 characteristics of the environment - e.g., financial resources, job opportunities, safety, neighbourhood, services and infrastructures, opportunities for leisure and recreation (Dolnicar et al., 2013; Neal et al., 2004; Sirgy et al., 2011; Skevington et al., 2004; Woo et al., 2015).

This suggests that perceptions on physical health, psychological wellbeing, social relationships and the characteristics of the environment may have a major impact on the perception of the overall QOL. Very little research concerning the impact of tourism on visitors' QOL has analysed the association between perceptions on specific domains of 
QOL and on overall QOL. However, Neal et al.'s (2004) research shows that satisfaction with non-leisure domains (e.g., financial situation, family, health, relationships) has a positive influence on visitors' life satisfaction. Moreover, the study of Sirgy et al. (2011) reveals that the impact of tourism on visitors' satisfaction with several life domains (e.g., satisfaction with social life, work life, health and safety, leisure and recreation, financial life, travel life, spiritual life) positively affect the visitors' overall satisfaction with life. Consequently, it is postulated that:

H10 Perceived tourism impacts on physical health will have a positive effect on the perceived tourism impacts on the overall QOL.

H11 Perceived tourism impacts on psychological features will have a positive effect on the perceived tourism impacts on the overall QOL.

H12 Perceived tourism impacts on social relationships will have a positive effect on the perceived tourism impacts on the overall QOL.

H13 Perceived tourism impacts on environment will have a positive effect on the perceived tourism impacts on the overall QOL.

\section{Methodology}

\subsection{Survey instrument and sampling approach}

In order to test the model presented in the last section a questionnaire was administered to university students of the Aveiro University in Portugal. The questionnaire included questions related to travel behaviour, the impact of tourism on QOL and socio-demographic profile. In order to answer the questions about the travel behaviour and the impact of tourism on QOL, respondents were asked to consider their tourism trips undertaken in the last five years. As far as behaviour is concerned, respondents were requested to indicate, during the tourism trips, the frequency with which they undertook several tourism activities - including nature, cultural, recreational and training activities - and the frequency with which they were in contact with residents in various places - monuments, events, food and beverage establishments, places of nightlife animation, nature places and in the street. Both questions were answered using a five-point Likert-type scale from 1 'never' to 5 'very frequently'. These questions were prepared based on literature concerning tourism activities undertaken by young visitors (e.g., Kim and Jogaratnam, 2003; Richards, 2007) and on tourist-host interactions (in this case, several items were selected in order to represent the contexts of interaction identified by De Kadt, 1979). Respondents were also asked to provide information about the impact of the tourism trips on several domains of their QOL - physical health, social relationships, psychological features and environmental conditions - and on overall QOL. In this case individuals had to indicate their level of agreement with several statements using a five-point Likert scale from 1 'completely disagree' to 5 'completely agree'. The statements were created based on items of the WHOQOL-BREF scale and on some literature of QOL from the field of tourism (Carneiro and Eusébio, 2011; Eusébio and Carneiro, 2011; Skevington et al., 2004) (see Appendix). The questionnaire ended with questions regarding socio-demographic features. 
The population of the study corresponded to the students of one university located in the centre of Portugal - the University of Aveiro. This university, in 2011, encompassed more than 12,000 students, from all the regions of Portugal and a considerable amount of foreign students, from a wide range of fields of study - about $55 \%$ of Sciences and Engineering and about $45 \%$ of Social Sciences and Arts. Moreover, the population of students under study is quite balanced in terms of gender (50\% male and $50 \%$ female). Respondents were selected using a quota sampling approach based on gender and area of study. In the period of April and May of 2011, the questionnaires were administered personally by researchers. A total of 412 completed questionnaires were obtained. In the sample there is a higher proportion of females (56\%), singles $(97 \%)$ and young tourists living in cities $(58 \%)$. The respondents are very young (the average age was about 21.71$)$.

\subsection{Data analysis methods}

Partial least squares structural equation modelling (PLS-SEM), using the SmartPLS 3.0 (Ringle et al., 2014), was used to validate the measures developed and test the hypotheses. PLS-SEM, a prediction-oriented variance-based approach, focusing on endogenous target constructs, which aims at maximising their explained variance (Hair et al., 2012), is well suited to handling complex models incorporating both reflective constructs (when the construct causes the measurement of the indicator variables) and formative constructs (when the indicator variables cause the measurement of the construct) and has less restrictions regarding assumptions about data (Hair et al., 2014). This analysis also accommodates non-normally distributed data, which often occurs in behavioural studies (Chin, 1998), since it uses bootstrapping to empirically estimate standard error for its parameter estimates (Gefen and Rigdon, 2011; Henseler et al., 2012). Consequently, there was no need to check the normality in the distributions. Moreover, constructs with fewer items or just one can be used. Due to its flexibility, PLS has emerged as a popular alternative to covariance-based structural equation modelling (CB-SEM) in empirical tourism research (e.g., Amaro and Duarte, 2015; García et al., 2012).

\section{Findings and discussion}

PLS path modelling analysis encompasses two stages. First, the evaluation of the measurement model, focusing on the analysis of each construct, is carried out. In a second stage the structural model was assessed in order to test the hypotheses underlying the conceptual model proposed in this study

\subsection{Measurement model}

The model proposed in this research includes both reflective and formative constructs. All first-order constructs are reflective, while the second-order constructs (containing two layers of constructs that, in this study, correspond to Participation in tourism activities and Tourist-host interaction level) are formative. The assessment of the measurement model will thus comprise the evaluation of reflective constructs and, subsequently, the evaluation of formative constructs. 


\subsubsection{Reflective constructs}

As suggested by Hair et al. (2014) and Henseler et al. (2009), the assessment of reflective constructs was carried out by analysing the reliability of the multiple-item scales, convergent validity and discriminant validity.

The reliability of the constructs was analysed using composite reliability, since it has been considered a more accurate measurement than Cronbach's alpha (Fornell and Larcker, 1981). As presented in Table 1, in the measurement model under analysis, the composite reliabilities of all constructs are higher than 0.77 , surpassing the reference value of 0.7 suggested by several authors (e.g., Bagozzi and Yi, 1988; Fornell and Larcker, 1981; Hair Jr. et al., 1998). Moreover, all factor loadings are equal to or greater than 0.66 , exceeding the threshold value of 0.6 suggested in the literature (Henseler et al., 2009).

The convergent validity was evaluated through the average variance extracted (AVE). As presented in Table 1, all first-order constructs have an AVE higher than 0.50, attesting to a good convergent validity of the scales used.

Finally, discriminant validity was assessed following Fornell and Larcker's (1981) guidelines, to examine if a construct is more strongly related to its own measures than to any other construct. Table 2 shows the correlations between constructs, where the square root of each construct's AVE (the diagonal elements) is higher than its correlations with any other construct. These results indicate an appropriate discriminant validity of the constructs.

Table 1 Measurement statistics of construct scales

\begin{tabular}{|c|c|c|c|c|c|c|}
\hline Construct/indicators & Mean & $\begin{array}{l}\text { Standard } \\
\text { deviation }\end{array}$ & $\begin{array}{l}\text { Indicator } \\
\text { loading }\end{array}$ & $t$-value & $C R$ & $A V E$ \\
\hline Nature activities & 2.56 & 0.928 & & & 0.859 & 0.603 \\
\hline Visiting protected areas & 2.66 & 1.161 & 0.816 & 34.290 & & \\
\hline Observing nature & 2.89 & 1.227 & 0.796 & 32.573 & & \\
\hline Visiting historic villages & 2.44 & 1.199 & 0.748 & 25.186 & & \\
\hline Walking on trails & 2.25 & 1.178 & 0.743 & 24.575 & & \\
\hline Cultural activities & 2.85 & 0.980 & & & 0.884 & 0.655 \\
\hline Visiting monuments & 2.85 & 1.266 & 0.862 & 50.618 & & \\
\hline Visiting historic sites & 3.2 & 1.162 & 0.809 & 38.352 & & \\
\hline Visiting museums & 2.63 & 1.194 & 0.790 & 32.105 & & \\
\hline Participating in cultural events & 2.7 & 1.174 & 0.774 & 31.209 & & \\
\hline Recreation activities & 3.63 & 0.987 & & & 0.79 & 0.656 \\
\hline Going to nightlife places & 3.38 & 1.208 & 0.902 & 16.489 & & \\
\hline Going to the beach & 3.88 & 1.209 & 0.706 & 5.549 & & \\
\hline Training activities & 1.73 & 0.891 & & & 0.857 & 0.750 \\
\hline Participating in training courses & 1.7 & 1.010 & 0.886 & 32.834 & & \\
\hline $\begin{array}{l}\text { Participating in } \\
\text { seminars/congresses/conferences }\end{array}$ & 1.77 & 1.047 & 0.846 & 21.158 & & \\
\hline
\end{tabular}

Notes: CR: composite reliability; AVE: average variance extracted; t-value was obtained with the bootstrapping procedure (5,000 samples) and are significant at the 0.001 level, n.a - not applicable. 
Table 1 Measurement statistics of construct scales (continued)

\begin{tabular}{|c|c|c|c|c|c|c|}
\hline Construct/indicators & Mean & $\begin{array}{l}\text { Standard } \\
\text { deviation }\end{array}$ & $\begin{array}{l}\text { Indicator } \\
\text { loading }\end{array}$ & t-value & $C R$ & $A V E$ \\
\hline Interaction in attractions & 2.40 & 1.042 & & & 0.806 & 0.676 \\
\hline In events & 2.24 & 1.278 & 0.823 & 25.715 & & \\
\hline In monuments & 2.57 & 1.257 & 0.821 & 23.264 & & \\
\hline Interaction in tourism services & 3.13 & 0.957 & & & 0.842 & 0.640 \\
\hline In F\&B establishments & 3.23 & 1.149 & 0.854 & 52.026 & & \\
\hline In other commercial establishments & 2.86 & 1.176 & 0.784 & 24.380 & & \\
\hline In places of nightlife animation & 3.31 & 1.269 & 0.759 & 24.608 & & \\
\hline Interaction in open air spaces & 3.17 & 0.982 & & & 0.78 & 0.639 \\
\hline In the street & 3.04 & 1.238 & 0.802 & 28.054 & & \\
\hline In nature places & 3.31 & 1.217 & 0.796 & 24.726 & & \\
\hline Physical health & 2.63 & 0.963 & & & 0.853 & 0.592 \\
\hline To increase my work ability & 2.43 & 1.238 & 0.790 & 32.173 & & \\
\hline $\begin{array}{l}\text { To increase my abilities to perform } \\
\text { daily activities }\end{array}$ & 2.38 & 1.257 & 0.781 & 29.300 & & \\
\hline To improve my mobility & 2.55 & 1.311 & 0.774 & 26.433 & & \\
\hline To increase my energy & 3.21 & 1.202 & 0.731 & 24.055 & & \\
\hline Psychological features & 2.66 & 0.983 & & & 0.884 & 0.605 \\
\hline To increase my self-esteem & 2.83 & 1.329 & 0.849 & 53.479 & & \\
\hline Have a more meaningful life & 2.66 & 1.313 & 0.807 & 38.769 & & \\
\hline To increase my positive feelings & 3.12 & 1.196 & 0.781 & 35.020 & & \\
\hline To decrease my negative feelings & 2.75 & 1.331 & 0.776 & 25.79 & & \\
\hline $\begin{array}{l}\text { To increase my satisfaction with my } \\
\text { body image }\end{array}$ & 1.95 & 1.126 & 0.662 & 17.352 & & \\
\hline Social relationships & 2.671 & 0.976 & & & 0.827 & 0.615 \\
\hline To improve my personal relations & 3.15 & 1.178 & 0.819 & 38.434 & & \\
\hline To increase support from my friends & 2.35 & 1.237 & 0.779 & 26.503 & & \\
\hline $\begin{array}{l}\text { To improve the relationships in my } \\
\text { household }\end{array}$ & 2.51 & 1.303 & 0.754 & 22.697 & & \\
\hline Environment & 3.18 & 0.909 & & & 0.831 & 0.552 \\
\hline To increase my access to information & 2.84 & 1.256 & 0.805 & 39.735 & & \\
\hline $\begin{array}{l}\text { To increase my opportunities to } \\
\text { expand my knowledge }\end{array}$ & 3.5 & 1.196 & 0.754 & 27.702 & & \\
\hline $\begin{array}{l}\text { To increase my opportunities for } \\
\text { doing leisure and recreation activities }\end{array}$ & 3.43 & 1.186 & 0.744 & 27.802 & & \\
\hline $\begin{array}{l}\text { To increase my opportunities to be in } \\
\text { a healthier environment }\end{array}$ & 2.97 & 1.259 & 0.663 & 17.219 & & \\
\hline Overall quality of life & & & & & 1 & n.a. \\
\hline To increase my overall quality of life & 3.19 & 1.308 & 1.000 & n.a. & & \\
\hline
\end{tabular}

Notes: CR: composite reliability; AVE: average variance extracted; t-value was obtained with the bootstrapping procedure $(5,000$ samples $)$ and are significant at the 0.001 level, n.a - not applicable. 
Table 2 Discriminant validity of the constructs - correlations between constructs

\begin{tabular}{|c|c|c|c|c|c|c|c|c|c|c|c|c|}
\hline \multicolumn{2}{|c|}{ Constructs } & 1 & 2 & 3 & 4 & 5 & 6 & 7 & 8 & 9 & 10 & 11 \\
\hline 1 & $\begin{array}{l}\text { Nature } \\
\text { activities }\end{array}$ & 0.777 & & & & & & & & & & \\
\hline 2 & $\begin{array}{l}\text { Cultural } \\
\text { activities }\end{array}$ & 0.568 & 0.810 & & & & & & & & & \\
\hline 3 & $\begin{array}{l}\text { Recreation } \\
\text { activities }\end{array}$ & 0.034 & 0.049 & 0.810 & & & & & & & & \\
\hline 4 & $\begin{array}{l}\text { Training } \\
\text { activities }\end{array}$ & 0.207 & 0.234 & 0.032 & 0.866 & & & & & & & \\
\hline 5 & $\begin{array}{l}\text { Interaction in } \\
\text { attractions }\end{array}$ & 0.307 & 0.472 & -0.005 & 0.143 & 0.822 & & & & & & \\
\hline 6 & $\begin{array}{l}\text { Interaction in } \\
\text { tourism } \\
\text { services }\end{array}$ & 0.105 & 0.150 & 0.418 & 0.114 & 0.257 & 0.800 & & & & & \\
\hline 7 & $\begin{array}{l}\text { Interaction in } \\
\text { open air spaces }\end{array}$ & 0.361 & 0.310 & 0.206 & 0.150 & 0.353 & 0.478 & 0.799 & & & & \\
\hline 8 & Physical health & 0.313 & 0.313 & 0.156 & 0.232 & 0.274 & 0.279 & 0.326 & 0.769 & & & \\
\hline 9 & $\begin{array}{l}\text { Psychological } \\
\text { features }\end{array}$ & 0.244 & 0.246 & 0.172 & 0.148 & 0.223 & 0.294 & 0.323 & 0.748 & 0.778 & & \\
\hline 10 & $\begin{array}{l}\text { Social } \\
\text { relationships }\end{array}$ & 0.232 & 0.281 & 0.222 & 0.100 & 0.290 & 0.335 & 0.315 & 0.679 & 0.706 & 0.784 & \\
\hline 11 & Environment & 0.401 & 0.463 & 0.127 & 0.189 & 0.412 & 0.366 & 0.514 & 0.676 & 0.626 & 0.605 & 0.743 \\
\hline
\end{tabular}

Note: Numbers in italic represent the square roots of the AVEs.

\subsubsection{Formative constructs}

Once the overall quality of the reflective constructs' measures was confirmed, the second-order constructs included in the conceptual model proposed (Figure 1) participation in tourism activities and tourist-host interaction level - were considered. The assessment of the quality of second-order constructs comprised three stages. First, the quality of first-order constructs (which influences the second-order constructs) was tested in the previous section, and all requirements were met. In the second stage, the multicollinearity among the first-order constructs was examined. Finally, the weights and significance level of the first-order constructs on the second-order constructs were analysed.

The multicollinearity was analysed through the variation inflation factor (VIF). The VIF values vary between 1.003 and 2.859, and are lower than 5 as suggested by Hair et al. (2012), thus revealing no collinearity problems. As shown in Table 3, all first-order construct weights are significant and higher than 0.10 , positively influencing the secondorder constructs, as suggested in the literature. Cultural and nature activities emerge as the first-order constructs with more influence on the formative construct participation in tourism activities. On the other hand, interaction in the open air and in tourism attractions are the first-order constructs which have a higher impact on tourist-host interaction level. 
Table 3 Weights of the first-order constructs on the second-order construct

\begin{tabular}{lccc}
\hline 2nd order contruct & 1st order constructs & Weight & t-value \\
\hline Participation in & Nature activities & 0.375 & $3.853^{* * *}$ \\
tourism activities & Cultural activities & 0.541 & $5.566^{* * *}$ \\
& Recreation activities & 0.393 & $4.155^{* * *}$ \\
& Training activities & 0.185 & $2.404^{*}$ \\
Tourist-host & Attractions & 0.405 & $5.618^{* * *}$ \\
interaction level & Open air spaces & 0.530 & $6.063^{* * *}$ \\
& Tourism services & 0.352 & $3.857^{* * *}$ \\
\hline
\end{tabular}

Notes: $* * * \mathrm{p}<0.001 ; * * \mathrm{p}<0.01 ; * \mathrm{p}<0.05$ based on 5,000 bootstraps.

\subsection{Structural model}

After having ensured the measurement model reliability and validity, the structural model was estimated in order to test the hypotheses proposed in the conceptual model (Figure 1). In this context, both the model's predictive power and the relationships between the constructs were examined (Figure 2).

Figure 2 Structural model assessment

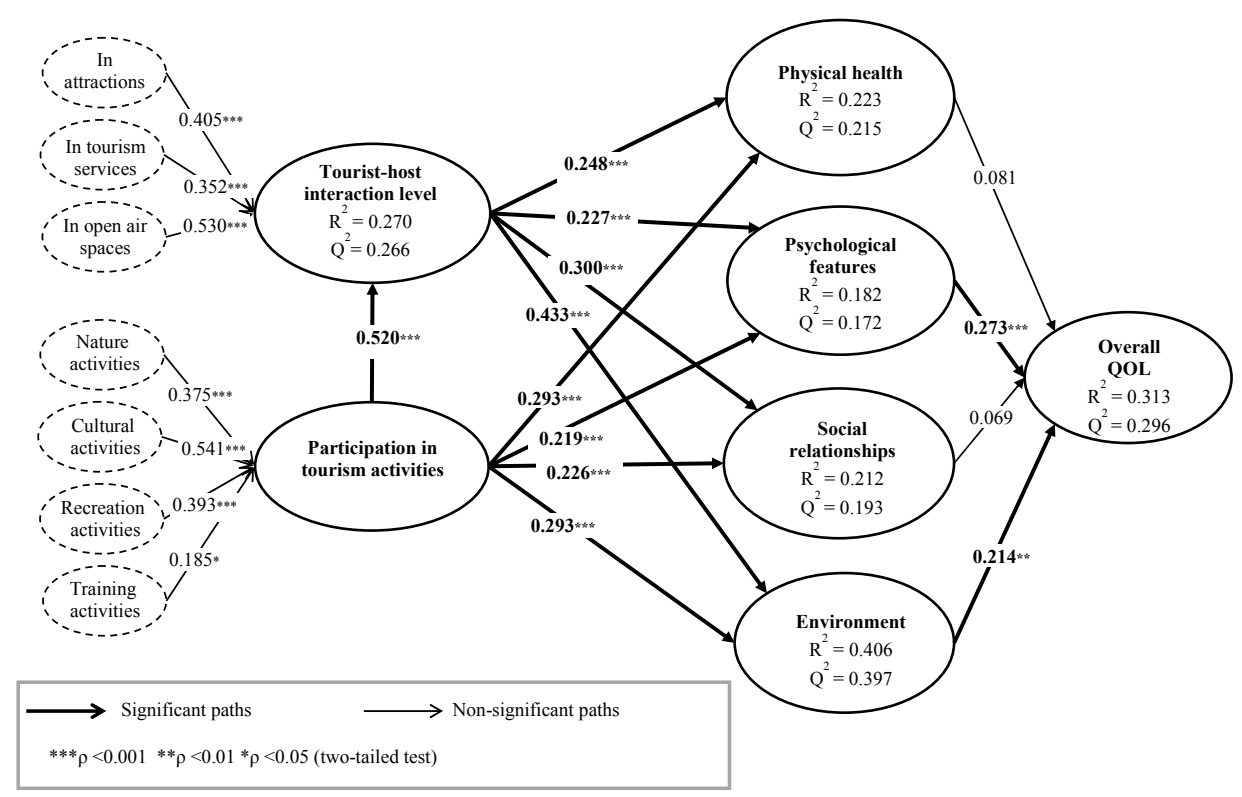

To evaluate the predictive power of the research model the explained variance $\left(R^{2}\right)$ and Stone-Geisser's $Q^{2}$ technique were used. Findings presented in Figure 2 reveal that the 
model has a considerably good prediction power since the $R^{2}$ values vary between 0.182 and 0.406 and the $Q^{2}$ values (model's predictive relevance) range from 0.172 to 0.397 , showing the predictive importance of endogenous constructs. The constructs with higher variance explained by the model were the perceived tourism impacts on environment and on overall QOL $\left(R^{2}=0.406\right.$ and $R^{2}=0.313$, respectively) followed by tourist-host interaction level $\left(R^{2}=0.270\right)$. On the other hand, the model only explained $18.2 \%$ of the variance of perceived tourism impacts on psychological features. As far as the hypotheses are concerned, the findings reveal that only two hypotheses are not supported (Figure 2 and Table 4).

The first hypothesis predicted that participation in tourism activities had a positive impact on tourist-host interaction level, which was confirmed, registering the strongest impact of the model $(\beta=0.52, p<0.001)$. This reveals the strong power of tourism activities to stimulate tourist-host interactions, as discussed in the literature review section (Carneiro and Eusébio, 2012; Kim, 2012; Su et al., 2014).

The findings also demonstrated a positive and significant influence of participation in tourism activities on all domains of QOL (hypotheses 2 to 5), especially on physical health $(\beta=0.29, p<0.001)$ and on environment $(\beta=0.29, p<0.001)$. When considering total effects (Table 5), this impact is greatly intensified in all the domains of QOL, with the total impact being higher on environment and on physical health. As suggested by Moscardo (2009), the results highlight that carrying out tourism activities may improve physical health. Findings also support some literature (e.g., Kim, 2012; Sirgy et al., 2011; Tse, 2014) which suggests that tourism activities may contribute to getting to know other places and to having more positive attitudes towards the environment (e.g., increasing access to information, increasing knowledge, creating more opportunities for being in healthier environments).

Regarding hypotheses 6 to 9, tourist-host interaction level was found to significantly influence all the QOL domains, with its highest impacts being on environment $(\beta=0.43$, $p<0.001)$ and, understandably, social relationships $(\beta=0.30, p<0.001)$. These findings emphasise the relevance of promoting social encounters between tourists and hosts in order to maximise the impacts of tourism on the youth tourists' QOL.

Finally, hypotheses 10 to 13 proposed that the impact of tourism on all QOL domains analysed influences the overall QOL. Results show that only two domains of QOL reveal a significant positive impact on overall QOL. Psychological features recorded the strongest and most positive effect on overall QOL $(\beta=0.27, p<0.001)$, followed by environment $(\beta=0.21, p<0.01)$. Although there is a need to expand research in this field, these findings corroborate other studies carried out (e.g., Eusébio and Carneiro, 2011), revealing the importance that the perceived impacts of tourism in the psychological domain and on environmental features has in improving tourists' overall QOL.

Moreover, it should be stressed that both participation in tourism activities and tourist-host interaction level also have a significant indirect impact on the perceived impact of tourism on youth tourists' overall QOL (Table 5), which shows that it is of utmost importance to offer tourists the opportunity to engage in various tourism activities and to interact with hosts in several contexts. 
Table 4 Hypotheses testing

\begin{tabular}{llc}
\hline Path & & Result \\
\hline H1 & Participation in tourism activities -> Tourist-host interaction & Supported \\
H2 & Participation in tourism activities -> Physical health & Supported \\
H3 & Participation in tourism activities -> Psychological features & Supported \\
H4 & Participation in tourism activities -> Social relationships & Supported \\
H5 & Participation in tourism activities -> Environment & Supported \\
H6 & Tourist-host interaction -> Physical health & Supported \\
H7 & Tourist-host interaction -> Psychological features & Supported \\
H8 & Tourist-host interaction -> Social relationships & Supported \\
H9 & Tourist-host interaction -> Environment & Supported \\
H10 & Physical health -> Overall QOL & Not supported \\
H11 & Psychological features -> Overall QOL & Supported \\
H12 & Social relationships -> Overall QOL & Not supported \\
H13 & Environment -> Overall QOL & Supported \\
\hline
\end{tabular}

Table 5 Direct, indirect and total effects

\begin{tabular}{|c|c|c|c|c|}
\hline Path & Direct & Indirect & Total & t-value \\
\hline $\begin{array}{l}\text { Participation in tourism activities -> } \\
\text { Tourist-host interaction }\end{array}$ & 0.520 & - & 0.520 & $12.885 * * *$ \\
\hline $\begin{array}{l}\text { Participation in tourism activities -> } \\
\text { Physical health }\end{array}$ & 0.293 & 0.129 & 0.422 & $9.900 * * *$ \\
\hline $\begin{array}{l}\text { Participation in tourism activities -> } \\
\text { Psychological features }\end{array}$ & 0.219 & 0.140 & 0.359 & $8.478 * * *$ \\
\hline $\begin{array}{l}\text { Participation in tourism activities -> } \\
\text { Social relationships }\end{array}$ & 0.226 & 0.156 & 0.382 & $8.737 * * *$ \\
\hline $\begin{array}{l}\text { Participation in tourism activities -> } \\
\text { Environment }\end{array}$ & 0.293 & 0.225 & 0.518 & $13.697 * * *$ \\
\hline $\begin{array}{l}\text { Participation in tourism activities -> } \\
\text { Overall QOL }\end{array}$ & - & 0.269 & 0.269 & $8.248 * * *$ \\
\hline Tourist-host interaction -> Physical health & 0.248 & - & 0.248 & $4.512 * * *$ \\
\hline $\begin{array}{l}\text { Tourist-host interaction -> Psychological } \\
\text { features }\end{array}$ & 0.270 & - & 0.270 & $4.774 * * *$ \\
\hline $\begin{array}{l}\text { Tourist-host interaction }->\text { Social } \\
\text { relationships }\end{array}$ & 0.300 & - & 0.300 & $5.514 * * *$ \\
\hline Tourist-host interaction -> Environment & 0.433 & - & 0.433 & $9.750 * * *$ \\
\hline Tourist-host interaction -> Overall QOL & - & 0.207 & 0.207 & $6.075^{* * *}$ \\
\hline Physical health -> Overall QOL & 0.081 & - & 0.081 & 0.999 n.s. \\
\hline Psychological features-> Overall QOL & 0.273 & - & 0.273 & $3.910 * * *$ \\
\hline Social relationships -> Overall QOL & 0.069 & - & 0.069 & 1.077 n.s. \\
\hline Environment -> Overall QOL & 0.214 & - & 0.214 & $3.138 * *$ \\
\hline
\end{tabular}

Notes: $* * * \mathrm{p}<0.001 ; * * \mathrm{p}<0.01$ based on 5000 bootstrap samples; $\mathrm{n} . \mathrm{s}$. - not significant. 


\section{Conclusions and implications}

The research model developed and tested in a sample of university students through PLSSEM and presented in this paper, provides important insights regarding the factors that may influence the perception of the impacts of tourism on youth tourists' QOL, given the scarce number of studies in this field. The model examines the relationships between two important dimensions of the tourism experience - participation in tourism activities and tourist-host interaction - and perceived tourism impacts on youth tourists' QOL. The model proposed meets all the requirements regarding both the measurement and the structural models and explains around $31.3 \%$ of the variance of the perceived impacts of tourism on youth tourists' overall QOL.

The findings, which refer to a case study performed at a Portuguese university, reinforce the relevance of the engagement in tourism activities to increase tourist-host interactions and the crucial role of both tourism activities and tourist-host interaction in improving the impact of tourism on all the domains of QOL considered in the study physical health, psychological features, social relationships and environment - and, indirectly, to improve overall QOL. Moreover, the results also revealed the significant role of psychological features and environment domains of QOL in improving the impact of tourism on overall QOL. Despite the results corroborating some findings about the constructs analysed (e.g., Dolnicar et al., 2013; Kim and Jogaratnam, 2003; McCabe et al., 2010; Pizam et al., 2000; Reisinger and Turner, 1998; Sinkovics and Penz, 2009), the absence of studies that simultaneously examine the relationships between all these constructs makes the comparison of the results with other findings difficult.

This study provides several theoretical contributions that permit some advances in the research regarding tourism impacts on QOL. It enables to increase the knowledge concerning two important dimensions of the tourism experience - participation in tourism activities and tourist-host interactions - as determinants of the tourism impact on QOL. Another important contribution is the empirical evidence generated regarding the moderating role of tourist-host interaction between the participation in tourism activities and the impact of tourism on several domains of QOL. The research also provides relevant insights concerning the measurement of the QOL construct in tourism and on the relationships between several domains of this construct and the impact of tourism on overall QOL. This study also permits us to expand knowledge on the youth tourism market that, as previously stated, is an important market segment, since it is very resilient to constraints such as natural features and acts of terrorism and is in the first stages of the travel career (Richards, 2007; WYSE Travel Confederation/UNWTO, 2011).

The findings of this study also provide important implications for planners and managers of tourism destinations that intend to attract the youth tourism market. First, as the results evidence that participation in tourism activities has an important role in increasing the impact of tourism on QOL, it is important to provide tourism products that promote the participation in various kinds of tourism activities (e.g., cultural, sportive and recreational activities). Considering the important role of tourism activities in stimulating tourist-host interaction it is crucial to offer tourism activities that involve the participation of local residents as guides or in co-producing activities (e.g., gastronomy and handicraft workshops) where both tourist and host may have an active role. Moreover, given the important role of tourist-host interaction in improving the tourism impacts on QOL it is 
of paramount relevance that the managers of the tourism industry provide an environment and atmosphere during tours which encourage social interaction with local people.

Despite the theoretical and practical contributions of this study, some limitations may be identified. First, the present study is limited in scope, since it focuses on the youth tourism market, specifically on students of a Portuguese university. It would be interesting to replicate this research and test the research model proposed among the youth tourism market in other countries to analyse the potential influence of cultural differences and to replicate it in other market segments (e.g., senior market). In the present study only the social encounters between tourists and hosts were analysed. Furthermore, only the frequency of these encounters in several places was examined. In order to improve the measurement of this concept, future studies should incorporate broader analyses of social contact in tourism, including interaction between tourists and the frequency of different types of interactions (e.g., sharing meals with other visitors and hosts, exchanging gifts with other visitors and hosts). Moreover, as the aim of this study was not to identify the best method to analyse the structural relationship under study, we have not proceeded with comparisons/robustness tests using alternative estimation methods. This exercise would be an interesting topic for further research in this field. Finally, the model could be improved by incorporating other factors that may influence the impacts of tourism on tourists' QOL (e.g., motivations) in order to increase the predictive power of the model. This is a promising research area which still is in its initial stages, and it is especially important to develop research that contributes to design tourism products that permit an improvement of the impact of tourism on youth tourists' QOL.

\section{References}

Alexander, Z., Bakir, A. and Wickens, E. (2010) 'An investigation into the impact of vacation travel on the tourist', International Journal of Tourism Research, Vol. 12, No. 5, pp.574-590.

Amaro, S. and Duarte, P. (2015) 'An integrative model of consumers' intentions to purchase travel online’, Tourism Management, Vol. 46, pp.64-79.

Andereck, K.L. and Nyaupane, G. (2011) 'Exploring the nature of tourism and quality of life perceptions among residents', Journal of Travel Research, Vol. 50, No. 3, pp.248-260.

Andereck, K.L., Valentine, K.M., Knopf, R.C. and Vogt, C.A. (2005).'Residents' perceptions of community tourism impacts', Annals of Tourism Research, Vol. 32, No. 4, pp.1056-1076.

Bagozzi, R. and Yi, Y. (1988) 'On the evaluation of structural equation models', Journal of the Academy of Marketing Science, Vol. 16, No. 1, pp.74-94.

Bicikova, K. (2014) 'Understanding student travel behavior: a segmentation analysis of British university students', Journal of Travel \& Tourism Marketing, Vol. 31, No. 7, pp.854-867.

Bond, N., Packer, J. and Ballantyne, R. (2015) 'Exploring visitor experiences, activities and benefits at three religious tourism sites', International Journal of Tourism Research, Vol. 17, No. 5, pp.471-481.

Carneiro, M.J. and Eusébio, C. (2011) 'Segmentation of tourism market using the impact of tourism on quality of life', Tourism \& Management Studies, No. 7, pp.91-100.

Carneiro, M.J. and Eusébio, C. (2012) 'Tourist-host interaction: a cluster analysis of the youth market', International Journal of Tourism Anthropology, Vol. 2, No. 3, pp.213-229.

Chin, W.W. (1998) 'The partial least squares approach to structural equation modelling, in Marcoulides, G.A (Ed.): Modern Methods for Business Research, pp.295-336, Lawrence Erlbaum, Mahwah, NJ. 
Dann, G.M.S. (2002) 'Senior tourism and quality of life', Journal of Hospitality \& Leisure Marketing, Vol. 9, No. 1, pp.5-19.

De Kadt, E. (1979) Tourism: Passport to development? Perspectives on the Social and Cultural Effects of Tourism in Developing Countries, Oxford University Press, New York, NY.

Dolnicar, S., Lazarevski, K. and Yanamandram, V. (2013) 'Quality of life and tourism: a conceptual framework and novel segmentation base', Journal of Business Research, Vol. 66, No. 6, pp.724-729.

Eusébio, C. and Carneiro, M.J. (2011) 'Determinants of tourism impact on tourists' quality of life', International Journal of Leisure and Tourism Marketing, Vol. 2, No. 4, pp.313-336.

Eusébio, C. and Carneiro, M.J. (2012) 'Determinants of tourist-host interactions: an analysis of the university student market', Journal of Quality Assurance in Hospitality and Tourism, Vol. 13, No. 2, pp.123-151.

Finsterwalder, J. and Laesser, C. (2013) 'Segmenting outbound tourists based on their activities: toward experiential consumption spheres in tourism services?', Tourism Review, Vol. 68, No. 3, pp.21-43.

Fornell, C. and Larcker, D.F. (1981) 'Evaluating structural equation models with unobservable variables and measurement error', Journal of Marketing Research, Vol. 18, No. 1, pp.39-50.

Frändberg, L. (2010) 'Activities and activity patterns involving travel abroad while growing up: the case of young swedes', Tourism Geographies: An International Journal of Tourism Space, Place and Environment, Vol. 12, No. 1, pp.100-117.

García, J.A., Gómez, M. and Molina, A. (2012) 'A destination-branding model: an empirical analysis based on stakeholders', Tourism Management, Vol. 33, No. 3, pp.646-661.

Gefen, D. and Rigdon, E.E. (2011) 'Editor's comments: an update and extension to SEM guidelines for administrative and social science research', MIS Quarterly, Vol. 35, No. 2, pp.iii-xiv.

Hair Jr., J.F., Anderson, R.E., Tatham, R.L. and Black, W.C. (1998) Multivariate Data Analysis, 5th ed., Prentice-Hall International, Upper Saddle River, New Jersey.

Hair, J.F., Hult, G.T.M., Ringle, C. and Sarstedt, M. (2014) A Primer on Partial Least Squares Structural Equation Modeling (PLS-SEM), SAGE Publications, Thousand Oaks.

Hair, J.F., Ringle, C.M. and Sarstedt, M. (2012) 'Partial least squares: the better approach to structural equation modeling?', Long Range Planning, Vol. 4, Nos. 5-6, pp.312-319.

Henseler, J., Ringle, C. and Sinkovics, R. (2009) 'The use of partial least squares path modeling in international marketing', in Sinkovics, R.R. and Ghauri, P.N. (Eds.): New Challenges to International Marketing (Advances in International Marketing, Volume 20), pp.277-319, Emerald Group Publishing Limited, Bingley.

Henseler, J., Ringle, C.M. and Sarstedt, M. (2012) 'Using partial least squares path modeling in advertising research: basic concepts and recent issues', in Okazaki, S. (Ed.): Handbook of Research on International Advertising, pp.252-276, Edward Elgar Publishing Ltd., Cheltenham and Northampton, doi: 10.4337/9781848448582.00023.

Kastenholz, E., Carneiro, M.J., Eusébio, C. and Figueiredo, E. (2013) 'Host-guest relationships in rural tourism: evidence from two Portuguese villages', Anatolia, Vol. 24, No. 3, pp.367-380.

Kim, J. (2012) 'Exploring the experience of intergroup contact and the value of recreation activities in facilitating positive intergroup interactions of immigrants', Leisure Sciences: An Interdisciplinary Journal, Vol. 34, No. 1, pp.72-87.

Kim, J-H. (2010) 'Determining the factors affecting the memorable nature of travel experiences', Journal of Travel \& Tourism Marketing, Vol. 27, No. 8, pp.780-796.

Kim, K. and Jogaratnam, G. (2002) 'Travel motivations: a comparative study of asian international and domestic American college students', Journal of Travel and Tourism Marketing, Vol. 13, No. 4, pp.61-82.

Kim, K. and Jogaratnam, G. (2003) 'Activity preferences of Asian international and domestic American university students: An alternate basis for segmentation', Journal of Vacation Marketing, Vol. 9, No. 3, pp.260-265. 
McCabe, S., Joldersma, T. and Li, C. (2010) 'Understanding the benefits of social tourism: linking participation to subjective well-being and quality of life', International Journal of Tourism Research, Vol. 12, No. 6, pp.761-773.

Michalkó, G., Kiss, K., Kovács, B. and Sulyok, J. (2009) 'The impact of tourism on subjective quality of life among Hungarian population', Hungarian Geographical Bulletin, Vol. 58, No. 2, pp.121-136.

Moscardo, G. (2009) 'Tourism and quality of life: towards a more critical approach', Tourism and Hospitality Research, Vol. 9, No. 2, pp.159-170.

Murphy, L. (2001) 'Exploring social interactions of backpackers', Annals of Tourism Research, Vol. 28, No. 1, pp.50-67.

Nawijn, J., Marchand, M.A., Veenhoven, R. and Vingerhoets A.J. (2010) 'Vacationers happier, but most nor happier after a holiday', Applied Research Quality Life, Vol. 5, No. 1, pp.35-47.

Neal, J.D., Sirgy, M.J. and Uysal, M. (2004) 'Measuring the effect of tourism services on travelers' quality of life: further validation', Social Indicator Research, Vol. 69, No. 3, pp.243-277.

Phau, I., Shanka, T. and Dhayan, N. (2010) 'Destination image and choice intention of university student travellers to Mauritius', International Journal of Contemporary Hospitality Management, Vol. 22, No. 5, pp.758-764.

Pizam, A., Uriely, N. and Reichel, A. (2000) 'The intensity of tourist-host social relationship and its effects on satisfaction and change of attitudes: the case of working tourists in Israel', Tourism Management, Vol. 21, No. 4, pp.395-406.

Reisinger, Y. (2009) International Tourism: Cultures and Behaviour, Butterworth Heinemann, Oxford, UK.

Reisinger, Y. and Turner, L. (1998) 'Cultural differences between Mandarin-speaking tourists and Australian hosts and their impact on cross-cultural tourist-host interaction', Journal of Business Research, Vol. 42, No. 2, pp.175-187.

Reisinger, Y. and Turner, L.W. (2003) Cross-Cultural Behavior in Tourism, Elsevier Butterworth Heinemann, Oxford, UK.

Richards, G. (2007) New Horizons II: The Young Independent Traveller 2007, WYSE Travel Confederation, Amsterdam.

Ringle, C.M., Wende, S. and Becker, J-M. (2014) Smartpls 3, Hamburg [online] http://www.smartpls.com (accessed 15 April 2015).

Ryan, C. and Zhang, Z. (2007) 'Chinese students: Holiday behaviors in New Zealand', Journal of Vacation Marketing, Vol. 13, No. 2, pp.91-105.

Shanka, T., Ali-Knight, J. and Pope, J. (2002) 'Intrastate travel experiences of international students and their perceptions of Western Australia as a tourist destination', Tourism and Hospitality Research, Vol. 3, No. 3, pp.245-256.

Sibson, R., Scherrer, P., Ryan, M.M., Henley, N. and Sheridan, L. (2010) 'Is physical activity leisure or work? Exploring the leisure-tourism-physical activity relationship with holidaymakers on Rottnest Island, Western Australia', Annals of Leisure Research, Vol. 13, No. 4, pp.652-678.

Sinkovics, R.R. and Penz, E. (2009) 'Social distance between residents and international tourist-implications for international business', International Business Review, Vol. 18, No. 5, pp.457-469.

Sirgy, M.J., Kruger, P.S., Lee, D-J. and Yu, G.B. (2011) 'How does a travel trip affect tourists' life satisfaction?', Journal of Travel Research, Vol. 50, No. 3, pp.261-275.

Sirgy, M.J., Michalos, A.C., Ferriss, A.L., Esaterlin, R.A., Patrick, D. and Pavot, W. (2006) 'The quality-of-life (QOL) research movement: past, present, and future', Social Indicators Research, Vol. 76, No. 3, pp.343-466. 
Skevington, S.M., Lotfy, M. and O'Connell, K.A. (2004) 'The World Health Organization's WHOQOL-BREF quality of life assessment: psychometric properties and results of the international field trial: a report from the WHOQOL group', Quality of Life Research, Vol. 13, No. 2, pp.299-310.

Su, M.M., Long, Y., Wall, G. and Jin, M. (2014) 'Tourist-community interactions in ethnic tourism: Tuva villages, Kanas scenic area, China', Journal of Tourism and Cultural Change, Vol. 14, No. 1, pp.1-26.

Szczechowicz, B. (2012) 'The importance of attributes related to physical activity for the tourism product's utility', Journal of Sport \& Tourism, Vol. 17 No 3, pp.225-249.

Tangeland, T. (2011) 'Why do people purchase nature-based tourism activity products? A Norwegian case study of outdoor recreation', Scandinavian Journal of Hospitality and Tourism, Vol. 11, No. 4, pp.435-456.

Tangeland, T. and Aas, Ø. (2011) 'Household composition and the importance of experience attributes of nature based tourism activity products - a Norwegian case study of outdoor recreationists', Tourism Management, Vol. 32, No. 4, pp.822-832.

Theofilou, P. (2013) 'Quality of life: definition and measurement', Europe's Journal of Psychology, Vol. 9, No. 1, pp.150-162.

Thrane, C. (2008) 'The determinants of students' destination choice for their summer vacation trip', Scandinavian Journal of Hospitality and Tourism, Vol. 8, No. 4, pp.333-348.

Tourism Research and Marketing (2013) New Horizons III Executive Summary: A Global Study of the Youth and Student Traveller, WYSE Travel Confederation, Amsterdam.

Trainor, S., Delfabbro, P., Anderson, S. and Winefield, A. (2010) 'Leisure activities and adolescent psychological well-being', Journal of Adolescence, Vol. 33, No. 1, pp.173-186.

Tse, T.S.M. (2014) 'Does tourism change our lives?', Asia Pacific Journal of Tourism Research, Vol. 19, No. 9, pp.989-1008.

Wei, S. and Milman, A. (2002) 'The impact of participation in activities while on vacation on seniors' psychological wellbeing: a path model application', Journal of Hospitality \& Tourism Research, Vol. 26, No. 2, pp.175-185.

Woo, E., Kim, H. and Uysal, M. (2015) 'Life satisfaction and support for tourism development', Annals of Tourism Research, Vol. 50, pp.84-97.

WYSE Travel Confederation/UNWTO (2011) The Power of Youth Travel, WYSE Travel Confederation/UNWTO [online] http:affiliatemembers.unwto.org.publication/power-youthtravel (acessed 12 April 2015).

Xu, F., Morgan, M. and Song, P. (2009) 'Students' travel behaviour: a cross-cultural comparison of UK and China', International Journal of Tourism Research, Vol. 11, No. 3, pp.255-268. 


\section{Appendix}

\section{Question used to measure the students' perception of tourism impact on their $Q O L$}

To what extent do you agree that the tourism trips undertaken in the last five years contributed to increase your QOL on the following features? (Please choose, in each line, the option that best corresponds to your opinion, using a five-point scale from 1 'completely disagree' to 5 'completely agree')

\begin{tabular}{|c|c|c|c|c|c|}
\hline \multirow[t]{2}{*}{ Items } & $\begin{array}{l}\text { Completely } \\
\text { disagree }\end{array}$ & & & & $\begin{array}{l}\text { Completely } \\
\text { agree }\end{array}$ \\
\hline & 1 & 2 & 3 & 4 & 5 \\
\hline To increase my work ability & 1 & 2 & 3 & 4 & 5 \\
\hline $\begin{array}{l}\text { To increase my abilities to perform daily } \\
\text { activities }\end{array}$ & 1 & 2 & 3 & 4 & 5 \\
\hline To improve my mobility & 1 & 2 & 3 & 4 & 5 \\
\hline To increase my energy & 1 & 2 & 3 & 4 & 5 \\
\hline To increase my self-esteem & 1 & 2 & 3 & 4 & 5 \\
\hline Have a more meaningful life & 1 & 2 & 3 & 4 & 5 \\
\hline To increase my positive feelings & 1 & 2 & 3 & 4 & 5 \\
\hline To decrease my negative feelings & 1 & 2 & 3 & 4 & 5 \\
\hline To increase my satisfaction with my body image & 1 & 2 & 3 & 4 & 5 \\
\hline To improve my personal relations & 1 & 2 & 3 & 4 & 5 \\
\hline To increase support from my friends & 1 & 2 & 3 & 4 & 5 \\
\hline To improve the relationships in my household & 1 & 2 & 3 & 4 & 5 \\
\hline To increase my access to information & 1 & 2 & 3 & 4 & 5 \\
\hline $\begin{array}{l}\text { To increase my opportunities to expand my } \\
\text { knowledge }\end{array}$ & 1 & 2 & 3 & 4 & 5 \\
\hline $\begin{array}{l}\text { To increase my opportunities for doing leisure } \\
\text { and recreation activities }\end{array}$ & 1 & 2 & 3 & 4 & 5 \\
\hline $\begin{array}{l}\text { To increase my opportunities to be in a healthier } \\
\text { environment }\end{array}$ & 1 & 2 & 3 & 4 & 5 \\
\hline To increase my overall quality of life & 1 & 2 & 3 & 4 & 5 \\
\hline
\end{tabular}

